\title{
Result Clauses
}

\author{
Cécile Meier \\ Universität Frankfurt/Main
}

\section{Introduction}

Traditionally, resultative so is assumed to be a degree word. It has practically the same distribution as other degree operators, e.g. excessive too, equative $a s$, and the degree question word how. Most strikingly, so can combine with gradable adjectives like intelligent but not with non-gradable adjectives like apparent.

a. so/too/as/how intelligent

b. ${ }^{*}$ so/*too/*as/*how apparent

Therefore, result clause constructions are comparative in nature. Consider the sentence in (2).

(2) Martha is so tall that she can reach the top shelf.

In this sentence we compare Martha's tallness with some degree determined by the complement clause. The complement clause introduces an acceptability criterion for the tallness of Martha, in this case the height of the shelf in question.

It is, however, not clear, what is the exact role of $s o$ in the semantics of result clauses and, in particular, in what way determines the that-clause the acceptability criterion.

The picture gets more complicated if we consider result clause constructions with more than one so-phrase. I am going to call these constructions with Chomsky (1981) split-antecedent constructions. Consider the sentence in (3).

(3) So many girls brought so many boys to the party that the room couldn't hold them all.

How could we capture the meaning of such a construction? Intuitively, the number of girls that brought boys and the number of boys that brought girls are compared to some acceptability criterion that is determined by the that-clause.

This paraphrase leaves it open at first sight whether we have only one comparison, i.e. a comparison between the sum of the number of boys and girls and a standard of comparison, in this case the capacity of the room, or whether we have two comparions, i.e. one comparison where we compare the number of girls to an acceptability criterion and another comparison where we compare the number of boys to a possibly different acceptability criterion.

In this paper, I am going to argue that the second view is the correct one. A result clause contains as many comparisons as there are so's. And, I will show that this view allows us to analyse split-antecedent constructions strictly compositional. 
In the literature, there are not too many and only incomplete proposals on how to analyse result clauses. And most authors concentrate on syntactic (LF) characteristics of constructions with a single so-phrase. ${ }^{1}$

Liberman (1974: 87), e.g., proposes that, in split-antecedent constructions, every surface occurrence of $s o$ is interpreted by a degree variable. A (presumably invisible) semantic degree operator so relates two propositions: (a) the open proposition expressed by the main clause and (b) the proposition expressed by the that-clause. He proposes an LF-structure as in (4) for the sentence given in (3). A similar LF-structure is also defended in Guéron \& May (1984).

so[ $n$-many girls brought $m$-many boys][(that) the room couldn't hold them all]

However, the authors do not address the questions how the operator so binds the variables $m$ and $n$, how so is actually interpreted and how it relates to so in singleso-constructions and other comparative constructions.

In my dissertation, I tried to capture the meaning of result clauses with multiple heads in terms of a comparison between lists of degrees Meier 2000. A comparison of lists is defined as a comparison of the sum of the coordinates of each list. Based on this analysis, the sentence in (3) is predicted to be true in a situation if 55 girls brought 76 boys and the room only holds a hundred people since 55 plus 76 is more than 100. But this analysis faces several problems. Frist of all, the so's in split-antecedent constructions denote something different from so in a single head construction. The analysis is not strictly compositional. And second, the analysis is too simplistic. Consider the sentence in (5).

(5) So many people liked so many pictures that the show must go on.

Assume that the board of the exhibition agreed to prolong the exhibition if more than 4000 people like more than 150 pictures. The shows goes on if on the one hand 5069 people liked pictures and if on the other hand more than 151 pictures are liked by people. In this case we intuitively have two comparisons one for people and one for pictures. Summing up pictures and people would not make any sense.

In this paper, I will make the following claims: First, result clause constructions are best captured by an extraposition analysis. This claim is and remains controversial. To my knowledge, there is no theory yet that can capture all syntactic peculiarities of result clause constructions, but a version of a movement theory as proposed by Gereon Müller and Wolfgang Sternefeld in 1993 and elaborated in Müller (1995) predicts most of the critical syntactic features. In this respect, I am following the footsteps of Bresnan (1973), Guéron \& May (1984) etc. who also proposed an analysis in terms of extraposition.

Furthermore, resultative so is claimed to be a degree quantifier that operates on the meaning of the main clause and the meaning of the that-clause. Under the assumption that so has quantificational character, we are able to predict scope ambiguities in intensional contexts for example. Here I am following Heim (2000). The fact that there are scope ambiguities in constructions with resultative so and 
intensional operators is an additional argument against Kennedy's (1997) approach to adjectival semantics.

The third claim concerns the reconstruction of a suitable standard of comparison on the basis of the that-clause. I will argue that the that-clause in fact hides a conditional clause. The antecedent of this conditional is a copy of the main clause. And, the proposition expressed by the that-clause supplies the consequent. This assumption is already defended for German result clauses in Meier (2000). In particular, I am going to argue for a syntactic copying rule and against a duplication process triggered by the semantics of so. In this respect, I am arguing against my own analysis in Meier (2000) and against the approach in Heim (2000).

And finally, split-antecedent constructions are argued to have as many thatclauses as there are so-phrases. Only one of those that-clauses undergoes extraposition. The others are deleted before Spell-out. This position is similar to the position of Guéron \& May. At the level of LF, however, all deleted that-clauses are recovered and play a crucial role in the interpretation. Here, my position is different from the position in Guéron \& May.

The paper is organized as follows: In a first step, I will briefly discuss the syntactic derivation of the surface structure and the Logical Form of result clauses with a single head. Then I will propose a semantics for so. In a second step, I will review some properties of result clause constructions. And in a last step, I am going to show how the proposed analysis applies to constructions with multiple so-phrases.

\section{Syntactic derivation: an extraposition analysis}

In order to derive a suitable LF, I assume that so and the that-clause form a constituent that is usually named degree phrase, and that the degree phrase is basegenerated in the complement position to the adjective. Here, I am following the tracks of von Stechow (1993) and most recently Heim (2000). The sentence in (2) starts its life with the structure in (6-a). Now consider the structure in (6-b). This configuration represents the sentence in its surface structure. Extraposition brings the that-clause in sentence final position. Following Müller \& Sternefeld (1993), I assume that extraposition is successive cyclic adjunction to the right. This movement satisfies the so-called Principle of Unambiguous Binding (PUB). ${ }^{2}$

(6) a. [CP Martha is [ ${ }_{\mathrm{AP}}$ [DegP So [CP that she can reach for the top shelf]] tall]]

b. Extraposition of the that-clause

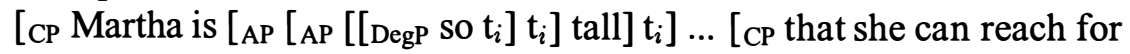
the top shelf $\left.]_{i}\right]$

With this approach we also predict apparent violations of the Complex NP constraint: see Rouveret (1978) for extensive discussion. 


\subsection{The Complex NP Constraint}

It seems not to matter how deeply the so phrase is embedded within a sentence. In (7) the that-clause successively crosses an AP, an NP, a PP and another NP by right adjunction.

(7) $\quad\left[\mathrm{NP}\left[\mathrm{NP}\right.\right.$ Plots [PP [PP by [NP [NP [AP [AP [[DegP so ti] ti] many] $\left.\mathrm{t}_{i}\right]$ conspirators $]$ $t_{i}$ ] $t_{i}$ ] $t_{i}$ ] have been hatched [CP that the government has jailed them $]_{i}$.

The extraposition account in terms of cyclic adjunction of the that-clause is however problematic.

\subsection{Clause boundedness of extraposition}

In some cases, it is not possible to cross a clause boundary with the that-clause by extraposition. (8-a), for example, is a possible surface structure. (8-b) with long extraposition of the that-clause is ungrammatical. ${ }^{3}$

Long extraposition is NOT possible

a. [NP The secret plans [ $\mathrm{CP}$ that so $\mathrm{t}_{1}$ many people know about [CP that the police has lost all credibility $\left.]_{1}\right]$ ] have finally been hatched

b. *[NP The secret plans [CP that so $t_{1}$ many people know about]] have finally been hatched [CP that the police has lost all credibility $]_{1}$

In other cases, however, extraposition is obviously not clause bound. Compare the sentence in (9). If the relative clause is adjoined to a bare noun, extraposition of the that-clause across a clause boundary seems to be possible. The last CP containing the result clause crosses the clause boundary of the relative clause.

Long extraposition IS possible

[NP Critics $_{i}$ [CP who have reviewed so $t_{1}$ many books]] were at the party [CP that I didn't have time to speak to them ${ }_{i}$ all $]_{1}$

Following Müller \& Sternefeld we do not have an explanation for (9). These authors stipulate that cyclic right adjunction to $\mathrm{CP}$ is not an option. This stipulation is necessary in order to explain the clause boundedness of extraposition, in general, and correctly rules out the configuration in (8-b).

In my opinion, the examples show that the extraposition theory is not yet perfect. But we do not have enough evidence, up to date, that it is false. ${ }^{4}$

\section{Semantic derivation: a degree analysis}

Now, let me try to determine what a result clause with a single so-phrase means. In my intuition, the sentence in (2), repeated here in (10), introduces first Martha's actual height on a scale. 
Martha is so tall that she can reach the top shelf.

The that-clause introduces possible values for Martha's height such that if she has these values she can reach the top shelf. In order to understand this, we have to assume counterfactually that Martha has a different height from her actual height. Finally, the minimum of these possible values is compared to the actual height of Martha. The that-clause therefore determines a critical lower bound of possible values. In fact, Martha's actual height has to be at least as high as some hypothetical height that is sufficient to reach the top shelf.

In terms of definite descriptions, I propose to paraphrase the meaning of (2) as in (11).

"The degree $d$ such that Martha is tall to $d$ (in the actual world) is greater than (or equal to) the minimal degree $d^{*}$ such that: if Martha is $d^{*}$-tall, she can reach the top shelf."

The main characteristics of the paraphrase are the following: The result clause construction seems to hide a conditional that is based on information of the main clause and on information of the that-clause. Furthermore, the information of the main clause appears twice in the paraphrase: once in front of the greater-than-orequal relation and once as a part of the if-clause. If we want to derive this fact compositionally, we have to propose some kind of duplication rule that targets the main clause.

In my dissertation (Meier 2000), I propose a semantic rule to duplicate the main clause information, as in (12). The that-clause, I assumed to be an incomplete conditional, i.e., a sentence that lacks an if-clause. And so is a function that combines the incomplete conditional (represented by $Q$ ) and the main clause. The main clause information (represented by $P$ ) entered the truth conditions twice, once in order to make the incomplete conditional complete and once to provide the object value in the actual world.

The meaning of so (with semantic duplication, Meier 2000)

$\llbracket \mathbf{s o \rrbracket}=f: D_{\langle s,<<s,\langle p, t>>,<\langle d, p\rangle, t>>>}$

For any world $w \in W$, any degree predicate $P \in D_{\langle d, p>}$ and any thatclause $Q \in D_{<s,\langle p, t>>}$ :

$f(w)(Q)(P)=1$ iff

$M A X\{d: P(d)(w))=1\} \geq M I N\{d *: Q(w)(P(d *)))=1\}$

In this paper, I am going to propose a syntactic rule of duplication and different truth conditions for $s o$, instead, as in (13). The reason for this move is the analysis of split-antecedent constructions that I will present below. I think that a uniform analysis of single so and multiple so constructions necessitates a syntactic rule of duplication.

Basically, the syntactic copying rule copies the main clause, replaces the trace in the copy by an empty category that is indexed with the same index as the trace and inserts the copy in the that-clause as if it were an if-clause to the sentence 
in the that-clause. The insertion operation, I assume to be IP-adjunction.

$$
\begin{aligned}
& \text { Duplication rule (first version) } \\
& {\left[[\text { DegP so }[\mathrm{CP} \text { that } \ldots[\mathrm{VP} \ldots]]]_{j}\left[\left[\mathrm{CP} \ldots\left[{ }_{\mathrm{AP}} \mathrm{t}_{j} \text { adjective }\right]\right]\right]\right.} \\
& {\left[\left[\mathrm{DegP} \text { so }\left[\mathrm{CP} \text { that }\left[\mathrm{IP}\left[\mathrm{CP}(\mathrm{if}) \ldots\left[\mathrm{AP}_{j} \mathrm{t}_{j} \text { adjective }\right]\right][\mathrm{VP} \ldots]\right]\right]\right]_{j}\right.} \\
& {\left[\left[\mathrm{CP} \ldots\left[\mathrm{AP}_{j} \text { adjective }\right]\right]\right]}
\end{aligned}
$$

Note that the duplication rule is applied after reconstruction of the that-clause to its base-generated position and after movement of the whole degree phrase to a sentence initial position. (14-a) is the surface configuration of our sentence in (10). (14-b) is the LF-representation that feeds the duplication rule.
a. [CP Martha is $\left[\mathrm{AP}\left[\mathrm{AP}\left[\left[\operatorname{DegP}\right.\right.\right.\right.$ So $\left.\left._{i}\right] \mathrm{t}_{i}\right]$ tall $\left.] \mathrm{t}_{i}\right] \ldots[\mathrm{CP}$ that she can reach the top shelf $\left.]_{i}\right]$
b. $\left[[\text { DegP so }[\mathrm{CP} \text { that she can reach the top shelf }]]_{j}\left[\mathrm{CP}\right.\right.$ Martha is [AP $_{j}$ tall]]]

If we apply the duplication rule to this example we derive the Logical Form in (15-b). At LF so relates the that-clause in form of an ordinary conditional if Martha is e-tall she can reach for the top shelf and the main clause Martha is t-tall.

$$
\begin{aligned}
& \text { a. }[[\mathrm{DegP} \text { so }[\mathrm{CP} \text { that }[\mathrm{VP} \text { she can reach the top shelf }]]]]_{j} \\
& \text { [CP Martha is [AP } \left.\mathrm{t}_{j} \text { tall] }\right] \Rightarrow \\
& \text { b. [[DegP so [CP that [IP [CP (if) Martha is [AP } \mathrm{e}_{j} \text { tall] ] [VP she can reach } \\
& \text { the top shelf] } \left.]]_{j} \text { [CP Martha is [AP } \mathrm{t}_{j} \text { tall] }\right]
\end{aligned}
$$

This is the structure that feeds the interpretation.

Adjectives denote functions of type $\langle s,\langle d,\langle e, t\rangle\rangle\rangle$ in the intensional framwork that I am using. tall for example is true for a world, a specific degree $d$ and an individual if the individual is tall to degree $d$, as in (16).

$$
\llbracket \text { tall } \rrbracket=f: D<s,<d,<e, t>>>
$$

For any world $w \in W$, degree $d \in D_{d}$ and individuals $a \in D_{e}$ :

$f(w)(d)(a)=1$

iff $a$ is tall to degree $d$ in $w$.

The trace of the DegP movement and the empty category $e$ are interpreted as degree variables. And these variables are bound by a version of a predicate abstraction. The movement index $j$ of the degree phrase in (15-b) triggers $\lambda$-abstraction over the degree variable of the main clause. At the level of that a $\lambda$-abstract of the conditional is created, abstracting away over the degree variable of the if -clause.

For the comparative morpheme so, I propose the meaning in (17). The general idea is that $s o$ relates two degree predicates: a degree predicate (Q) denoted by the (enriched) that-clause and a degree predicate $(\mathrm{P})$ denoted by the main clause. So maximizes the degree predicate denoted by the main clause and it minimizes the degree predicate denoted by the that-clause and it introduces the comparison 
relation. More specifically, the result clause construction is true if the maximal degree that satisfies the main clause in the world of utterance is greater or equal to the minimal degree that satisfies the proposition expressed by the that-clause.

$$
\begin{aligned}
& \text { The meaning of so (with syntactic duplication) }
\end{aligned}
$$

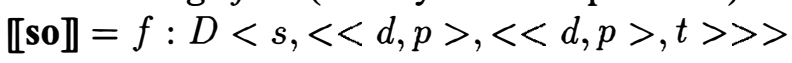

$$
\begin{aligned}
& \text { For any world } w \in W \text {, and any degree predicates } P, Q \in D_{<d, p>} \text { : } \\
& f(w)(Q)(P)=1 \text { iff } \\
& M A X\{d: P(d)(w)=1\} \geq M I N\{d *: Q(d *)(w)=1\}
\end{aligned}
$$

Maximality and minimality are defined standardly as in (18).

$$
\begin{array}{ll}
\text { a. } & M A X(P)=\iota d . P(d)=1 \& \forall d^{\prime}\left[P\left(d^{\prime}\right)=1 \Rightarrow d^{\prime} \leq d\right] \\
\text { b. } & M I N(P)=\iota d . P(d)=1 \& \forall d^{\prime}\left[P\left(d^{\prime}\right)=1 \Rightarrow d \leq d^{\prime}\right]
\end{array}
$$

On the semantics specified so far, (15-b) gets the truth conditions in (19), where $g$ is any variable assignment and $\mathrm{w}_{0}$ is a designated variable for the actual world.

$$
\begin{aligned}
& \operatorname{MAX}\left\{d: \text { Martha is } d \text {-tall in } g\left(w_{0}\right)\right\} \geq \\
& \operatorname{MIN}\left\{d^{*}: \text { if Martha is } d^{*} \text {-tall, she can in } g\left(w_{0}\right) \text { reach the top shelf }\right\}
\end{aligned}
$$

The maximal degree $d$, such that Martha is $d$-tall in the actual world is at least as great as the minimal degree $d^{*}$ such that if Martha is $d^{*}$-tall, she can reach the top shelf. Let me disregard for the moment that the actual height of Martha is maximalized. If we compare the truth conditions in (19) with our original intuitively motivated paraphrase in (11), we observe that they are identical. Thus, the analysis seems to work fine so far.

\section{Three arguments in favor of the analysis}

In the following, I am going to present three arguments in favor of this analysis.

\subsection{Binding phenomena}

Binding phenomena show that an extraposition analysis is preferred for result clause constructions over a base generation analysis. I am following in this respect basically the argumentation by Büring \& Hartmann (1995) with respect to PP-dependent clauses in German, for example. The relevant facts for result clauses are presented in (20). In (20-a) a subject quantifier binds a pronoun in a that-clause that is associated with the predicative AP. This configuration appears to be well-formed. In (20-b), however, an object quantifier binds a pronoun that is associated with the AP contained in the subject phrase. Such a configuration is not possible.

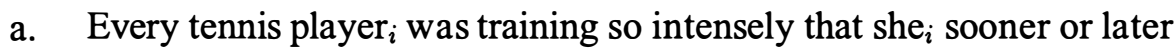
got injured. 
b. *So many people donated money to every radio station ${ }_{i}$ that it met $_{i}$ its ${ }_{i}$ year-end goals (in raising money).

For the grammatical case $(20-a)$, I assume that the so-phrase has narrow scope with respect to the quantifier at the level of LF. The quantifier is therefore in a c-command position and can bind the pronoun she, as in (21-a). In the ungrammatical case (20-b), the so-phrase has wide scope with respect to the object quantifier. The object quantifier is therefore not in a position to bind the pronoun at the level of LF, as in (21-b). ${ }^{5}$

a. $\quad\left[\mathrm{CP}[\mathrm{NP} \text { every tennis player }]_{i}\right]_{1}\left[\mathrm{CP}\left[\mathrm{DegP} \text { so that she }{ }_{i} \ldots\right]_{2} \mathrm{t}_{1}\right.$ was training $t_{2}$ intensely]]

b. ${ }^{*}\left[\mathrm{CP}\left[\mathrm{DegP} \text { so that } \mathrm{it}_{i} \ldots\right]_{2}\left[\mathrm{CP}\left[\mathrm{NP}_{2} \text { many people }\right]_{3}[\mathrm{CP}[\mathrm{NP}\right.\right.$ every radio station $\left._{i}\right]_{1} \mathrm{t}_{3}$ donated to $\left.\left.\left.\mathrm{t}_{1}\right]\right]\right]$

An analysis that base-generates the that-clause in the right periphery of the sentence may not predict these subject-object asymmetries in a straight forward way.

\subsection{Explicit/implicit modalization}

Kratzer (1978) argues that unmodalized conditionals are in fact modalized implicitly by a modal with universal force. And she shows that it is possible to add a modal denoting necessity to unmodalized conditionals without changing the meaning of the construction.

The same seems to hold for constructions with result clauses. Consider the example in (22). We can add a phrase like it was necessary to the that-clause without changing the truth conditions of the construction. (22-a) and (22-b) are identical in meaning.

a. She was so hot that she fainted.

b. She was so hot that it was necessary that she fainted.

This means that we have an argument by analogy for the existence of a conditional in result clause constructions. However, it is not possible to make the implicit conditional explicit.

\subsection{Scope interaction}

Truth conditional ambiguities corroborate the analysis of $s o$ as a quantifier. ${ }^{6}$ If the so-phrase occurs in the c-command domain of other operators at the surface structure we may observe usually more than one reading of the sentence. Consider, for example the sentence (23).

This sentence may either imply that the reason for us not to invite Bill for dinner is a claim by Mary. This is (23-a). Or the sentence can mean that Mary claimed a proposition in form of a result clause. (23-b) is compatible with the fact that we invited Bill for dinner, but (23-a) is not. 
Mary claimed that Bill was so weird that we didn't invite him to dinner.

a. 'We didn't invite Bill to dinner because Mary claimed that Bill was weird."

b. "Mary claimed that we didn't invite Bill to dinner because he was weird."

In order to derive this ambiguity, I propose the following LF configurations. In (24-a) the so-phrase has scope over the intensional operator claim and in (24-b) claim outscopes the so-phrase.

a. [[DegP so $[\mathrm{CP}$ that [VP we didn't invite him to dinner $]]_{j}[\mathrm{CP}$ Mary claimed that Bill was [ ${ }_{A P} t_{j}$ weird] ]

b. [CP Mary claimed that Bill was [DegP so [CP that [VP we didn't invite him to dinner] $]]_{j}\left[\mathrm{CP}_{[\mathrm{AP}} \mathrm{t}_{j}\right.$ weird $\left.\left.]\right]\right]$

These LFs get the interpretation in (25). In one reading (23) means (25-a): the maximal degree $d$ such that Mary claimed Bill was weird to degree $d$ is at least as great as the minimal degree $d^{*}$ such that if Mary claimed that Bill was weird to degree $d^{*}$, we don't invite him for dinner. In the other reading (23) means (25-b): Mary claimed that Bill's weirdness is at least as great as the minimal $d^{*}$ such that if Bill was $d^{*}$-weird we don't invite him for dinner.
a. $\quad M A X\{d:$ M. claimed that Bill was $d$-weird $\} \geq$ $M I N\left\{d^{*}:\right.$ if M. claimed that Bill was $d^{*}$-weird, we don't invite him for dinner $\}$
b. $\quad$ Mary claimed that $M A X\{d:$ Bill was $d$-weird $\} \geq$ $M I N\left\{d^{*}:\right.$ if Bill was $\mathrm{d}^{*}$-weird, we don't invite him for dinner $\}$

\section{Result clauses with multiple heads}

In the next step, I am going to show that this system is applicable to result clause constructions with split antecedents and that the predictions we derive from the analysis meet our intuitions about the meaning of such sentences. Let us consider our old sentence (5) repeated in (26).

So many people like so many pictures that the show must go on.

Intuitively, the fact that the show must go on, depends on how many people liked how many pictures. Disregard the impact of the standard of comparison for a moment. If we do that, (26) means something like (27). I call this the big picture. Assume that the value for the standard of comparison for the set of people is $d^{*}$ and the value for the standard of comparison for the set of pictures is $e^{*}$. And assume that the set of people and the set of pictures is not empty. Then (26) may be paraphrased by (27). That is, the big picture is a conjunction of two comparisons. 
The big picture

The cardinality of people that like pictures is at least as great as $d^{*}$ AND the cardinality of pictures that are liked by people is at least as great as $e^{*}$.

How do we determine the standards of comparison $d^{*}$ and $e^{*}$ ? It should be obvious what my proposal is going to be. The standards are determined by some implicit conditional that gives us a set of cardinalities. The cardinality of the set of people has to be at least as great as the minimal number $d$ that satisfies the conditional if $d$-many people like pictures the show must go on, as in (28-a). And the cardinality of the set of pictures has to be at least as great as the minimal number $e$ such that if $e$-many pictures are liked by people the show must go on, as in (28-b).

a. $\quad d^{*}=$ the minimal $d$ such that: if $d$-many people like pictures, the show must go on

b. $\quad e^{*}=$ the minimal $e$ such that: if $e$-many pictures are liked by people, the show must go on

What are the characteristics of this paraphrase if we put (27) and (28) together?

The first observation is that we have to take into account a certain parallelism. Consider the first conjunct in the big picture (27). The standard of comparison for the cardinality of the set of people is $d^{*}$ in (28-a) and $d^{*}$ is a cardinality of people, too. In other words, we compare the actual cardinality to a minimally sufficient cardinality of people. Hypothetical cardinalities of pictures seem to be irrelevant for the determination of the critical lower bound for people. The same structure can be found in the second conjunct in (27). If we compare the actual cardinality of pictures to some hypothetical minimum of pictures - this is $e^{*}$ in (28-b) - the hypothetical number of people is irrelevant.

I am going to capture this parallelism by a process of existential closure at the level of the that-clause.

The second observation is: The information of the main clause appears several times. Twice in the big picture (27) and once in each conditional. It is obvious that this multiplication of the main clause information might be handled by some variant of the syntactic duplication rule, I proposed above.

And the third observation is: the information of the that-clause the show must go on appears twice, once as a consequent of the standard of comparison $d^{*}$ in (28-a) and once as a consequent of the standard of comparison $e^{*}$ in (28-b). I am assuming that both instances of the that-clause are actually there.

In order to derive the surface structure of (26), I am assuming that one thatclause is extraposed to a sentence final position and one that-clause is deleted under identity. This is shown in (29).

a. $\left[\mathrm{CP}\left[{ }_{\mathrm{AP}}[\mathrm{DegP}\right.\right.$ So [CP that the show must go on] many] people like [AP [DegP so [CP that the show must go on]] many] pictures]

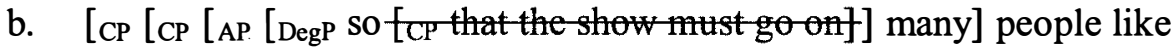
[AP [DegP so $t_{i}$ ] many] pictures] [CP that the show must go on $]_{i}$ ] 
More generally speaking, I assume that split-antecedent constructions contain as many that-clauses as there are so-phrases. Evidence for the fact that this is correct is given in (30). It is possible to have split-antecedent constuctions with more than one that-clause at surface structure. One that-clause may appear sentence internally. Paulien Rijkoek makes a similar claim in her dissertation. She even claims that two that-clauses can occur in sentence final position. ${ }^{7}$

(30) a. So many lectures that we had no time to attend them all have been given by such boring professors that we didn't WANT to attend them all.

b. So many people have so much money that they do not know what to do with it, that charity institutions would go bankrupt on the stamps needed to reach them all.

For the derivation of the LF, all deleted that-clauses are recovered and the extraposed that-clause is reconstructed to its base position. In (31) the degree phrases are raised to CP leaving the traces $t_{1}$ and $t_{2}$. This movement is an instance of quantifier raising and is type-driven.

(31) $\left[\mathrm{CP}[\mathrm{DegP} \text { So }[\mathrm{CP} \text { that the show must go on }]]_{1}[\mathrm{CP}[\mathrm{DegP}\right.$ so $[\mathrm{CP}$ that the show must go on $]]_{2}\left[\mathrm{CP}\left[\mathrm{NP}\left[\mathrm{AP}_{1}\right.\right.\right.$ many] people] like [NP [AP $\mathrm{t}_{2}$ many] pictures]]]]

This is the moment where the multiplication rule comes into play that targets the main clause information. According to this rule we copy the main clause as many times as there are so-phrases in the syntax. As in the case with single so the traces of the degree phrases are replaced by empty categories, the indices of the traces are copied. Then each copy is inserted as an if -clause to the propositions expressed by the that-clause.

Multiplication rule (revised version for $n$-many so-phrases)

a. $\left[\mathrm{CP}[\mathrm{DegP} \text { so }[\mathrm{CP} \text { that } \ldots[\mathrm{VP} \ldots]]]_{0} \ldots[\mathrm{CP}[\mathrm{DegP}\right.$ so $[\mathrm{CP}$ that ...

$[\mathrm{VP} \ldots]]]_{n}\left[\mathrm{CP} \ldots\left[\mathrm{AP}_{\mathrm{A}} \mathrm{t}_{0}\right.\right.$ adjective $] \ldots\left[\mathrm{AP}_{n}\right.$ adjective $\left.\left.] \ldots\right]\right] \Rightarrow$

b. $\left[\mathrm{CP}\left[\mathrm{DegP}\right.\right.$ so $\left[\mathrm{CP}\right.$ that $\left[\mathrm{CP}\right.$ (if)... [AP $\mathrm{e}_{0}$ adj. $] \ldots\left[\mathrm{AP}_{n}\right.$ adj. $\left.\left.] \ldots\right]\right] \ldots$

$[\mathrm{VP} \ldots]]_{0}$

[CP [DegP so [CP that [CP (if) ... [AP $\mathrm{e}_{0}$ adj.] ... [AP $\mathrm{e}_{n}$ adj.] ...]

$\ldots[\mathrm{VP} \ldots]]]_{n}$

$\left[\mathrm{CP} \ldots\left[\mathrm{AP} \mathrm{t}_{0}\right.\right.$ adj.] $\ldots\left[\mathrm{AAP}_{n}\right.$ adj.]]]

Let us now apply the multiplication rule to our example in (26). Multiplication in this case is triplication, as in (33). Both if-clauses are exact copies of each other. Both conditionals are assumed to determine a standard of comparison.

[CP [DegP1 so [CP that [IP [CP (if) [NP [AP $\mathrm{e}_{1}$ many] people]] like [NP [AP $\mathrm{e}_{2}$ many] pict.]]] the show must go on]] $]_{1}$ 
[CP [DegP2 so [CP that [IP

[CP (if) [NP [AP $\mathrm{e}_{1}$ many] people]] like [NP [AP e $\mathrm{e}_{2}$ many] pict.]]] the show must go on]] $]_{2}$

$\left[\mathrm{CP}\left[\mathrm{NP}\left[\mathrm{AP}_{1} \mathrm{t}_{1}\right.\right.\right.$ many] people]] like [NP [AP $\mathrm{t}_{2}$ many $]$ pictures $\left.\left.]\right]\right]$

How then is it possible to capture the parallelism, we just discovered a minute ago. Remember that the actual cardinality of people was compared in the paraphrase to some minimally possible hypothetical cardinality of people. The cardinality of the pictures was irrelevant to determine the standard of comparison. And the actual cardinality of the pictures was compared to some minimally possible hypothetical cardinality of pictures. In the second case the cardinality of people was irrelevant in order to determine the standard of comparison intuitively. Or in other words: The first conditional in (33) is supposed to determine a set of cardinalities of people and the second conditional is supposed to determine a set of cardinalities of pictures.

In order to capture this observation, I propose that one lambda operator is introduced at each level of that and this lambda operator only binds that degree variable that has the same index as the movement index of the so-phrase that heads the conditional. The remaining degree variables get bound by existential closure at the level of that.

In order to see the effect of existential closure and lambda abstraction, I will focus in the next step on the representation of the DegP1 of (26). Consider the tree in (34).

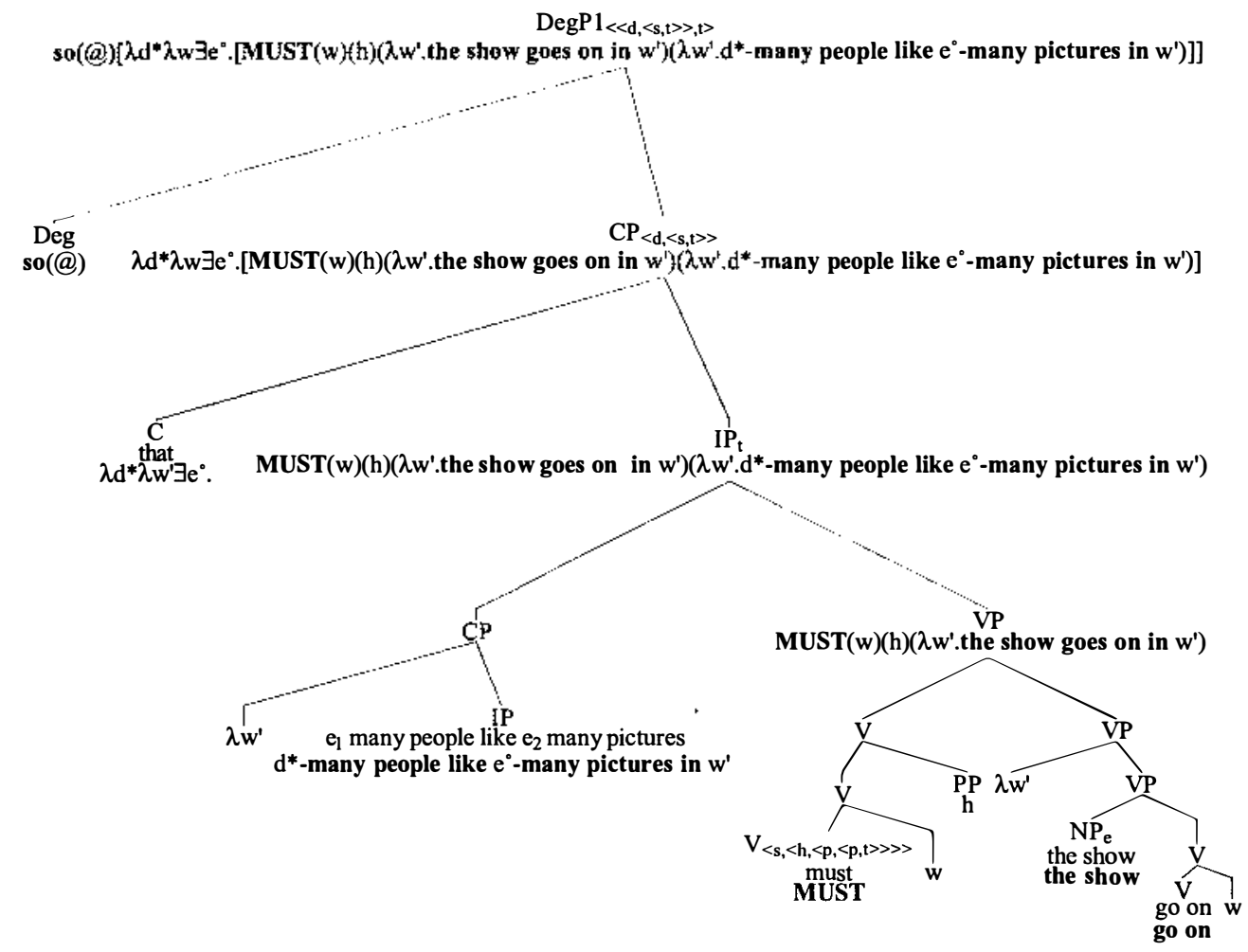


At the level of that, $\lambda$-abstraction applies to the degree variable that is indexed with the same index as the movement index of the degree phrase. The remaining free degree variable is existentially bound. The that-clause in the first DegP therefore denotes a set of cardinalities that the subject of the if -clause people has, as desired. The other degree phrase DegP2 is interpreted analogously. The that-clause in the second degree phrase denotes a set of cardinalities that the object of the if-clause pictures has. DegP1 and DegP2 only differ with respect to the movement indices that trigger $\lambda$-abstraction.

If we apply our semantic rules to the whole structure in (33), they assign the truth conditions in (35). The first line is a version of the big picture in (27). The standard of comparisons are minimal cardinalities that satisfy an existential statement.

$M A X\left\{d: M A X\{e: d-\right.$ many people like e-many pict. $\left.\} \geq e^{*}\right\} \geq d^{*}$ where

$d^{*}=\operatorname{MIN}\left\{d^{*}: \exists e^{\prime}\right.$ [if $d^{*}$-many people like $e^{\prime}$-many pictures, the show must go on] $\}$ and

$e^{*}=\operatorname{MIN}\left\{e^{*}: \exists d^{\prime}\right.$ [if $d^{\prime}$-many people like $e^{*}$-many pictures, the show must go on]\}

The key characteristics of this interpretation is that one comparison is embedded within the first component of the other comparison. The next task is to show that (35) indeed means something like the paraphrase in (27).

In order to derive the intuitive paraphrase in form of a conjunction from (35), I basically exploit the fact that statements with a maximality operator may be translated into existential statements if we assume Russell's theory of definite descriptions. Let us concentrate on the outer comparison, first. (36-a) is equivalent to (35). By the definition of maximality (36-b) and the definition of definite descriptions (36-c), we reformulate the outer comparison in terms of an existential statement, as in (36-d).

$$
\begin{array}{ll}
\text { a. } & M A X\{d: \varphi(d)\} \geq d^{*} \\
& \text { (with } \left.\varphi=\lambda r\left[M A X\{e: r \text {-many people like } e \text {-many pictures }\} \geq e^{*}\right]\right) \\
\text { b. } & \iota d . \varphi(d)=1 \& \forall d^{\prime}\left[\varphi\left(d^{\prime}\right)=1 \Rightarrow d^{\prime} \leq d\right] \geq d^{*} \text { (maximality) } \\
\text { c. } & \exists d\left[\varphi(d)=1 \&|\varphi|=1 \& \forall d^{\prime}\left[\varphi\left(d^{\prime}\right)=1 \rightarrow d^{\prime} \leq d\right] \& d \geq d^{*}\right. \\
& (\text { definite description) } \\
\text { d. } & \exists d\left[\varphi(d)=1 \& d \text { is unique \& } d \text { is maximal \& } d \geq d^{*}\right]
\end{array}
$$

The first conjunct of the existential statement in (36-d) is true if the inner comparison in (37-a) holds. By maximality and the definition for definite descriptions we derive the existential statement in (37-d), in analogy to the previous procedure.

$$
\begin{array}{ll}
\text { a. } & M A X\{e: d-\text { many people like } e \text {-many pictures }\} \geq e^{*} \\
\text { b. } & M A X\{e: \psi(e)\} \geq e^{*} \\
& \text { (with } \psi=\lambda r . d \text {-many people like } r \text {-many pictures) } \\
\text { c. } & \iota e . \psi(e)=1 \& \forall e^{\prime}\left[\psi\left(e^{\prime}\right)=1 \rightarrow e^{\prime} \leq e\right] \geq e^{*} \text { (maximality) }
\end{array}
$$


d. $\exists e\left[\psi(e)=1 \&|\psi|=1 \& \forall e^{\prime}\left[\psi\left(e^{\prime}\right)=1 \rightarrow e^{\prime} \leq e\right] \& e \geq e^{*}\right.$ (definite description)

e. $\exists e\left[\psi(e)=1 \& e\right.$ is unique \& $e$ is maximal \& $e \geq e^{*}$

If we put (36-d) and (37-e) together, we get the existential statement in (38).

$\exists d[\exists e[d$-many people like $e$-many pictures $\& e$ is unique $\& e$ is maximal $\& e \geq e *] \& d$ is unique \& $d$ is maximal \& $d \geq d^{*}$ ]

Every formula with a maximality operator in the truth conditions in (35) may be turned into a formula of predicate logic containing an existential statement. And one existential statement is nested into the other. But the existential quantifiers do not take scope with respect to each other.

(39-b) and (39-c), respectively, follow from (39-a). A short comparison will reveal that (39-b) and (39-c) together are the ingredients for our intuitive paraphrase in $(27) .^{8}$

a. $\exists d \exists e[d$ is unique \& $d$ is maximal \& $e$ is unique \& $e$ is maximal $\& d$-many people like $e$-many pictures $\left.\& e \geq e^{*} \& d \geq d^{*}\right]$

b. $\Rightarrow \exists d \exists e[d$ is unique $\& d$ is maximal $\& e$ is unique $\& e$ is maximal $\& d$-many people like $e$-many pictures $\& d \geq d^{*}$ ] (first conjunct of (27))

c. $\quad \Rightarrow \exists d \exists e[d$ is unique $\& d$ is maximal $\& e$ is unique $\& e$ is maximal $\& d$-many people like $e$-many pictures $\& e \geq e^{*}$ ( (second conjunct of (27))

If we applied the same method of interpretation to the sentence in (3), repeated here in (40), we, however, encounter a problem. It seems that the operation of existential quantification does not make the correct predictions.

(40) So many girls brought so many boys that the room couldn't hold them all.

(41) states the truth conditions we derive with the instrumentarium so far.

$$
M A X\left\{d: M A X\{e: d \text { - many girls brought e-many boys }\} \geq e^{*}\right\} \geq d^{*}
$$
where

a. $\quad d^{*}=\operatorname{MIN}\left\{d^{*}: \exists e^{\prime}\right.$ [if $d^{*}$-many girls brought $e^{\prime}$-many boys, the room cannot hold them all] $\}$ and

b. $\quad e^{*}=\operatorname{MIN}\left\{e^{*}: \exists d^{\prime}\right.$ [if $d^{\prime}$-many girls bring $e^{*}$-many boys, the room cannot hold them all] $\}$

The actual cardinality of girls that brought boys is compared to some minimally admissible cardinality of girls $d^{*}$, and the actual cardinality of boys that were brought by girls is compared to some minimally admissible cardinality of boys $e^{*}$. The nested comparison may be reformulated as in (42).

$\exists d \exists e[d$ is unique \& $d$ is maximal \& $e$ is unique \& $e$ is maximal \& $d$-many 
girls brought $e$-many boys $\left.\& e \geq e^{*} \& d \geq d^{*}\right]$

If we evaluate these truth conditions we predict the sentence to be true in a situation where 20 girls brought 70 boys and the room holds 100 people, contrary to our intuition. Why should this be the case? According to the truth conditions, the actual cardinality of the girls is compared to the minimal cardinality of girls such that there is some number of boys that the girls brought to the party and the room couldn't hold them. This minimum could be one girl that brought at least 100 boys. And one girl is less than 20 girls. The same argument can be made for the comparison of the actual cardinality of boys to some minimal cardinality of boys. It seems, therefore, that our method of interpretation is not capable of interpreting the mutual interdependence of the cardinalities of boys and girls, yet.

In order to repair this flaw of the analysis, I propose to reconsider the calculation of the admissibility criteria $d^{*}$ and $e^{*}$ in (41) and (42).

Intuitively, it is not just some cardinality of boys that could be brought by girls that is relevant for the calculation of the minimum of girls but the actual cardinality of boys, and it is not some cardinality of girls that brought boys that is relevant for the calculation of the minimum of boys but the actual cardinality of girls. The relevant admissibility criteria may be paraphrased as in (43), where $e_{0}$ refers to the number of boys that were actually brought by the girls to the party and $d_{0}$ refers to the number of girls that actually brought the boys to the party.

$$
\begin{aligned}
& \text { a. } d^{*}=\text { the minimal } d^{\prime} \text { such that: if } d^{\prime} \text {-many girls bring } e_{0} \text {-many boys, } \\
& \text { the room cannot hold them all } \\
& \text { b. } e^{*}=\text { the minimal } e^{\prime} \text { such that: if } e^{\prime} \text {-many boys are brought by } d_{0} \text {-many } \\
& \text { girls, the room cannot hold them all. }
\end{aligned}
$$

This paraphrase is plausible. If 20 girls brought 70 boys, $d^{*}$ is the minimal $d$ such that if $d$-many girls bring 70 boys, the room cannot hold them all. If the room is limited to 100 people, $d^{*}$ is equal to 31 and greater than $d$ and not at least as great. Therefore, the sentence in (26) is predicted to be false in such a situation, as desired. The minimum of girls depends on the actual number of boys and the minimum of boys depends on the actual number of girls.

If 70 girls brought 20 boys, $d^{*}$ is the minimal $d$ such that if $d$-many girls bring 20 boys, the room cannot hold them all. And, if the room is limited to 100 people, $d^{*}$ is equal to 81 and at least as great as $d$. But the minimal $e^{*}$ such that if 70 girls bring $e^{*}$-many boys, the room cannot hold them all, is equal to 31 and greater than the actual cardinality of boys. Again, the sentence in (26) is predicted to be false in such a situation, as desired.

The crucial point of the paraphrase is: we characterize the relevant cardinality of boys and girls, respectively, by using a definite description for the reference of $e_{0}$ the number of boys that were actually brought to the party by the girls in (43-a) and for the reference of $d_{0}$ the number of girls that actually brought the boys to the party in (43-b).

One way to think about the variables in technichal terms is the following: $d_{0}$ and $e_{0}$ are referential pronouns that are interpreted as simple free variables and 
get their interpretation by the utterance context. Their reference is anaphorically related to the maximal number of girls that brought boys and the maximal number of boys that are brought by girls. Since it is characteristic for E-type pronouns to be paraphrased by definite descriptions: see Heim \& Kratzer (1998) for discussion, the variables $d_{0}$ and $e_{0}$ in (43) are also natural candidates for E-type pronouns.

Therefore, I conclude that an interpretation of the empty categories in the hidden if -clause in terms of referential pronouns or E-type-pronouns makes more general predictions than simple existential closure at the level of that.

In a last step, I will give a hint to why truth conditions for so that rely on semantic duplication of the main clause information do not make the correct predictions for result clauses with split antencents. I repeat in (44) the meaning for $s o$ with semantic duplication. Remember that so duplicates the main clause information.

$$
\begin{aligned}
& \text { The meaning of so }(=(12) \\
& \llbracket \mathbf{s o} \rrbracket=f: D_{\langle s,<<s,\langle p, t>>,<\langle d, p>, t>>>}
\end{aligned}
$$

For any world $w \in W$, and any degree predicate $P \in D_{\langle d, p\rangle}$ and any that-clause $Q \in D_{\langle s,\langle p, t>>}: f(w)(Q)(P)=1$ iff

$$
M A X\{d: P(d)(w))=1\} \geq \operatorname{MIN}\{d *: Q(w)(P(d *)))=1\}
$$

In split-antecedent constructions the problem is the following: If we apply our rule for $s o$ to the outer $s o l$ in $(45-\mathrm{a})$, the inner $s o 2$ gets duplicated. Therefore, the truth conditions in (45-b) host three comparisons. And this is counterintuitive.

a. [CP [DegP1 so1 [CP that the show must go on] $] 1$ [CP [DegP2 so2 [CP that the show must go on] $]_{2}\left[\mathrm{CP}\left[\mathrm{NP}\left[\mathrm{AP} \mathrm{t}_{1}\right.\right.\right.$ many] people $\left.]\right]$ like [NP [AP $\mathrm{t}_{2}$ many] pictures]]]]

b. $M A X\{d: d$-many people like so many pictures that the show must go on $\} \geq M I N\left\{d^{*}\right.$ : if $d^{*}$-many people like so many pictures that the show must go on the show must go on

\section{Conclusion}

The current derivation of the meaning of single so and split-antecedent result clause constructions relies on the following assumptions: (1) There is one that-clause associated with each occurrence of so. (2) The sentential complement of a result clause construction is assumed to represent a hidden conditional. (3) This hidden conditional is recovered syntactically and not semantically, as previously assumed. (4) The antecedents of the conditionals are open propositions that are identical to the proposition expressed by the main clause. (5) $\lambda$-abstraction at the level of that is an index sensitive mechanism. (6) Variables in the that-clause that carry an index that is identcal to the movement index of the degree phrase that dominates the thatclause get bound by $\lambda$-abstraction. (7) Remaining free variables remain free and get a referential interpretation provided by the context of utterance. An operation of existential closure seems not to be appropriate. The binding mechanism depends on 
the syntactic function of the first maximal phrase that dominates the degree phrase. In other words, the maximal phrase that dominates a degree phrase in the main clause and the phrase that contains a degree variable bound by $\lambda$-abstraction in the antecedent of a hidden conditional have the same syntactic function. These assumptions enable us to derive the meaning of split-antecedent result clause constructions.

\section{Endnotes}

* I wish to thank Roger Schwarzschild, Ede Zimmermann and the participants of the SALT 11 conference for discussion on the topics of this paper.

1. The most important and influential is the article of Guéron \& May (1984). More recent attempt to resolve the problems is Rochemont \& Culicover (1990).

2. Principle of Unambiguous Binding Müller \& Sternefeld (1993: 461): A variable that is $\alpha$ bound must be $\beta$-free in the domain of the head of its chain (where $\alpha$ and $\beta$ refer to different types of positions). Movement through a specifier postion to an A-bar-position counts as improper in this account.

3. Compare the fundamental work in Rouveret (1978), Guéron \& May (1984) and Rijkhoek (1998).

4. I refer the reader to the discussion on (45) in Rochemont \& Culicover (1990) and recent work by Danny Fox and Jon Nissenbaum on this topic.

5. This argument presupposes that the object quantifier must not have wide scope with respect to the subject so-phrase at LF. See Kennedy (1997) and Heim (2000) on further discussion on this topic.

6. Ambiguities of result clauses were first discussed by Liberman (1974).

7. Guéron \& May (1984), however, dispute that fact.

8. The explanation for the meaning of split-antecedent constructions parallels actually an argument by von von Stechow (1984). He has a very similar method for deriving the meaning for multi-head comparatives.

\section{References}

Bresnan, Joan W. (1973): 'Syntax of the Comparative Clause Construction in English', Linguistic Inquiry 4, 275-343.

Büring, Daniel \& Katharina Hartmann (1995): All right!. In: Extraction and Extraposition. Amsterdam/Philadelphia:Benjamins, pp. 279-211.

Chomsky, Noam (1981): Lectures on Government and Binding. Dordrecht: Foris.

Guéron, Jacqueline \& Robert May (1984): 'Extraposition and Logical Form', Linguistic Inquiry 15(1), 1-31.

Heim, Irene (2000): Degree Operators and Scope. to appear in Proceedings of SALT 10 edited by B. Jackson and T. Matthews. CLC Publications, Cornell Univ. 
Heim, Irene \& Angelika Kratzer (1998): Semantics in Generative Grammar. Vol. 13 of Blackwell Textbooks in Linguistics, Malden/MA: Blackwell.

Kennedy, Christopher (1997): Polar Opposition and the Ontology of Degrees. ms.,http://www.ling.nwu.edu/ kennedy/Docs/xpolarlsp.ps.

Kratzer, Angelika (1978): Semantik der Rede: Kontexttheorie, Modalwörter, Konditionalsätze. Königstein: Scriptor.

Liberman, Mark (1974): On Conditioning the Rule of Subj.-Aux.-Inversion. In: E. K. . J. Hankamer, ed., Papers from the Fifth Annual Conference of the North Eastern Linguistics Society, Harvard University, Cambridge, Massachusetts. pp. 77-91.

Meier, Cécile (2000): Konsekutive Konstruktionen und relative Modalität. PhD thesis, Universität Tübingen.

Müller, Gereon (1995): On Extraposition and Successive Cyclicity. In: On Extraposition and Extraction In German. Amsterdam/Philadelphia: John Benjamins Publishin Company, pp. 213-243.

Müller, Gereon \& Wolfgang Sternefeld (1993): 'Improper Movement and Unambiguous Binding', LI 24, 461-502.

Rochemont, Michael \& William Culicover (1990): English Focus Constructions and the Theory of Grammar. Cambridge: Cambridge University Press.

Rouveret, Alain (1978): Result Clauses and Conditions on Rules. In: S. Keyser, ed., Recent Transformational Studies in European Languages. Cambridge/MA: MIT Press, pp. 159-178.

von Stechow, Arnim (1984): 'Comparing Semantic Theories of Comparison', Journal of Semantics 3, 1-77.

von Stechow, Arnim (1993): Die Aufgaben der Syntax. In: J. Jacobs, A. von Stechow, W. Sternefeld \& T. Vennemann, eds, Syntax: Ein internationales Handbuch zeitgenössischer Forschung, Vol. 9.1. Berlin: de Gruyter, pp. 1-88. 